\title{
Convenient Methods for the Synthesis of Chiral Amino Alcohols and Amines
}

\author{
Mariappan Periasamy*, Ramani Gurubrahamam, Nalluri Sanjeevakumar, Manasi Dalai, \\ Laxhmaiah Alakonda, Polimera Obula Reddy, Sundaram Suresh, Sakilam Satishkumar, \\ Meduri Padmaja, Meda Narsi Reddy, Surisetti Suresh, Shaik Anwar, G. P. Muthukumaragopal, \\ Pothiappan Vairaprakash, and Muthu Seenivasaperumal
}

\begin{abstract}
Simple, convenient methods have been developed using readily available, easy-to-handle reagents to access a variety of chiral amino alcohols and amines, which have considerable potential for applications in asymmetric organic transformations. Scholars from this laboratory in India have made significant contributions to this field, which is the subject of the current review.
\end{abstract}

Keywords: Amines · Asymmetric borane reduction · Aziridinium ions · Chiral amino alcohols · Cyclohexene epoxide $\cdot$ Naphthols $\cdot$ Reductive coupling $\cdot$ Resolution $\cdot$ Ring opening $\cdot$ Tröger base

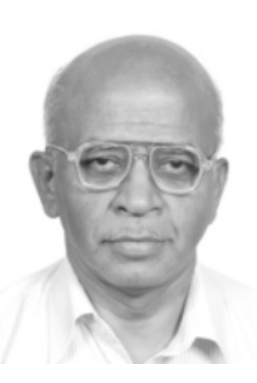

M a r i a p p a $n$ Periasamy is a native of Srivilliputtur, Tamil Nadu, India. He received his early education in schools and colleges around Srivilliputtur and earned his $\mathrm{PhD}$ degree for research work in Organic Chemistry at the Indian Institute of Science (IISc), Bangalore during 1975-1979 (Mentor: Professor M. V. Bhatt). After a postdoctoral stint at Purdue University, U.S.A during 19791982 with Professor H. C. Brown on the 'Nonclassical Ion Problem', he joined the faculty of the School of Chemistry, University of Hyderabad in July 1982. His research interests are on the 'Development of Convenient Routes to Organometallics \& Chiral Reagents and Renewable Energy Sources'. He has so far published over 180 research papers. He has received several honors including the Shanti Swarup Bhatnagar Prize (1996) and the JC Bose National Fellowship (2006-2016) awarded by the Government of India.
${ }^{\star}$ Correspondence: Prof. M. Periasamy School of Chemistry

University of Hyderabad Central University P.O.

Hyderabad-500046, INDIA

E-mail: mpsc@uohyd.ernet.in

\section{Introduction}

A major hindrance to organic synthesis research work in India is the difficulty in accessing useful but highly air-sensitive reagents such as borane reagents, metal carbonyls and the expensive chiral reagents. Accordingly, about 30 years back, we initiated research efforts to develop convenient methods to access such reagents using readily available inexpensive starting materials. Gratifyingly, some of the methods developed in this laboratory have been also followed up by leading researchers abroad. Convenient methods developed to access chiral amino alcohols and amine derivatives (Fig. 1) are reviewed in this article.

\section{Synthesis of Chiral Amino Alcohols from Chiral Amino Acids}

Chiral amino alcohols are an important class of organic compounds. Several chiral amino alcohol moiety-containing derivatives are useful in medicinal chemistry as therapeutic agents for a wide variety of human diseases and disorders. ${ }^{[1]}$ $\beta$-Amino alcohols are generally prepared from naturally occurring $\alpha$-amino acids by simple reduction or through the transformation of the corresponding ester derivatives. ${ }^{22]}$ Chiral (S)- $\alpha, \alpha$-diphenyl-2pyrrolidinemethanol (1) was utilized extensively in numerous asymmetric transformations. [3] It has attracted profound

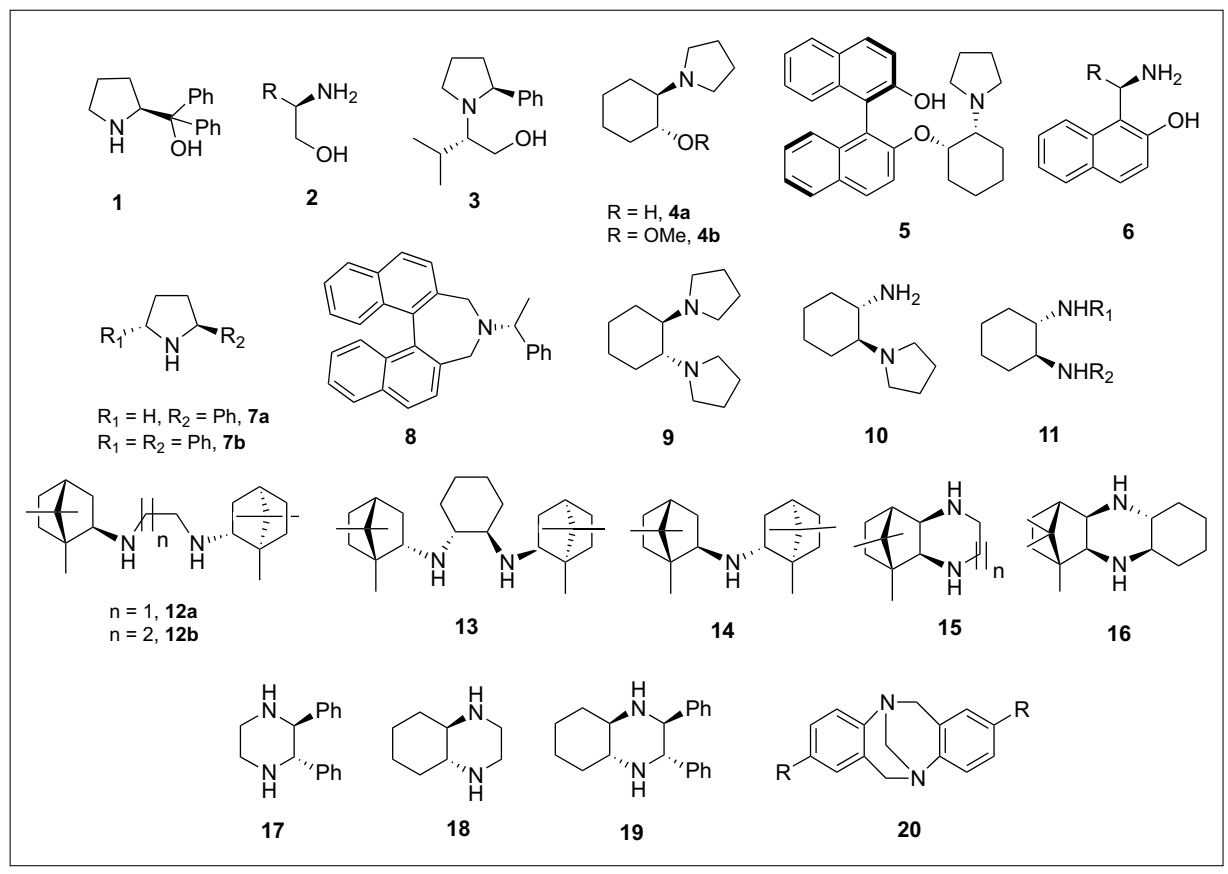

Fig.1. Chiral amino alcohols and amines. 


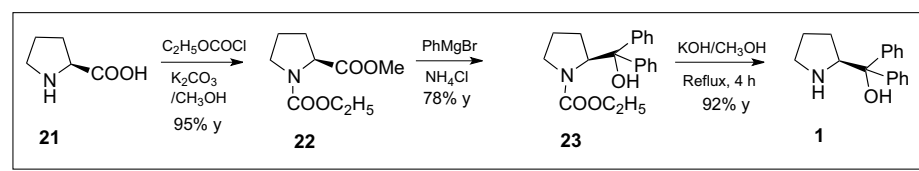

Scheme 1.

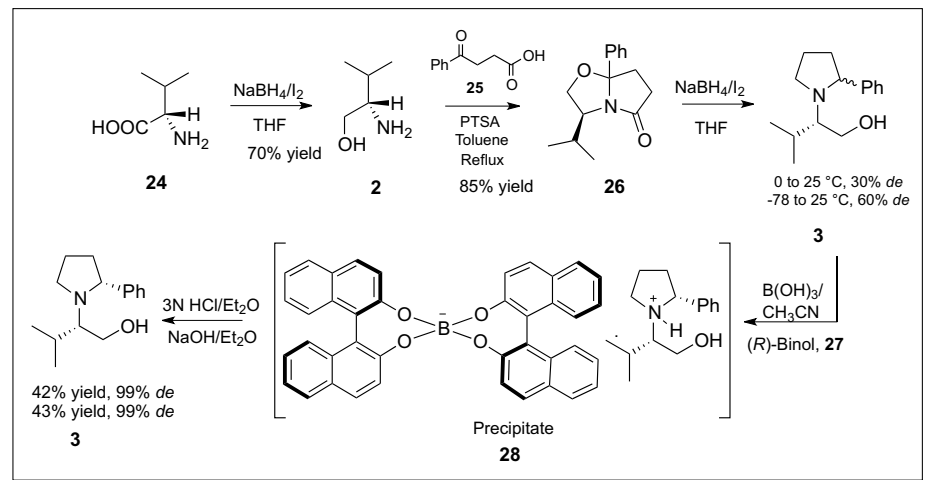

Scheme 2.

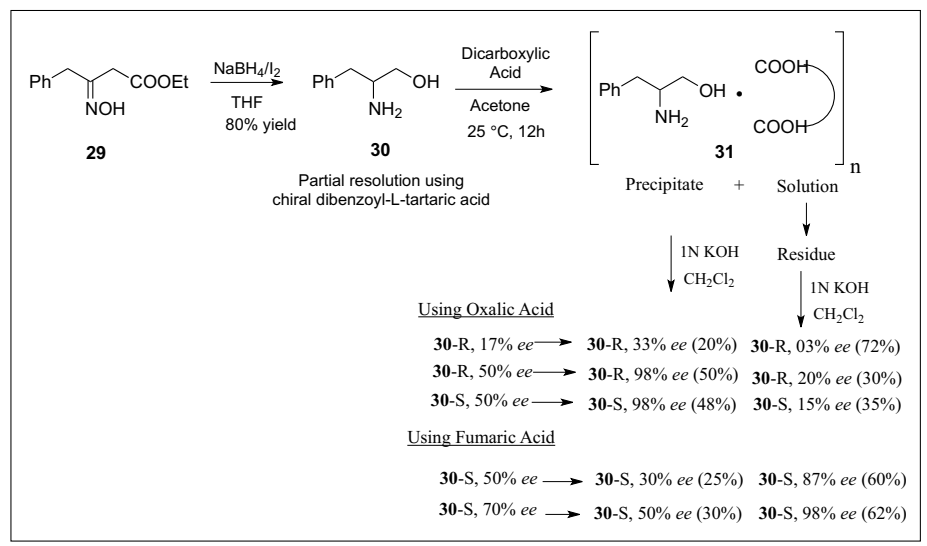

Scheme 3.

interest as it is the precursor for the preparation of the CBS (Corey-Bakshi-Shibata) oxazaborolidine catalyst useful for the highly enantioselective borane reduction of ketones. ${ }^{[4]}$ Originally, it was synthesized by $N$-protection, esterification, phenyl Grignard addition and $N$-deprotection using expensive reagents. ${ }^{[5]}$ Also, it was accessed via enantioselective lithiation of $\mathrm{N}$-protected pyrrolidine using expensive chiral sparteine.[6] We have developed a simplified and convenient method for accessing chiral $(S)$ - $\alpha, \alpha$-diphenyl-2pyrrolidine methanol (1) involving one step $N, O$-protection of $(S)$-proline (21) and deprotection of the carbamate intermediate using $\mathrm{KOH} / \mathrm{CH}_{3} \mathrm{OH}$ under refluxing conditions (Scheme 1). ${ }^{[7]}$

Synthesis of chiral 2-substituted $N$-glycinol pyrrolidine derivative $\mathbf{3}$ was previously achieved via $\mathrm{AlH}_{3}$ reduction of Meyers' lactam 26 prepared from the corresponding amino acid. ${ }^{[8]}$ We have observed that the reduction of the intermediate bicyclic lactam 26 is readily achieved using the inexpensive $\mathrm{NaBH}_{4} / \mathrm{I}_{2}$ reagent system at 0 ${ }^{\circ} \mathrm{C}$ and $-78{ }^{\circ} \mathrm{C}$ (Scheme 2). Unfortunately,

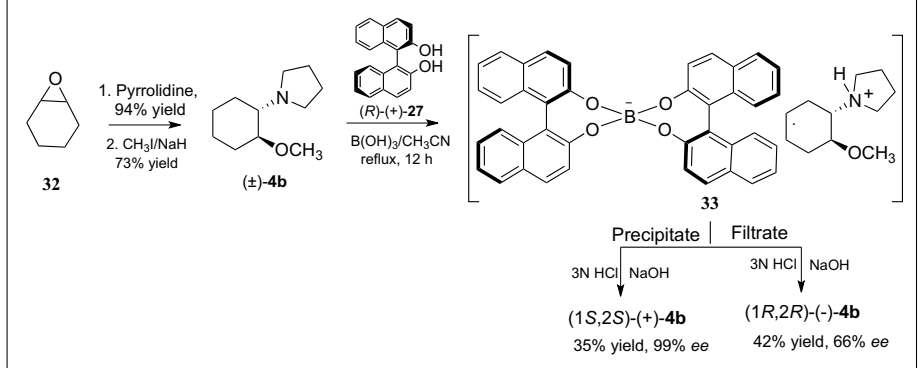

Scheme 4

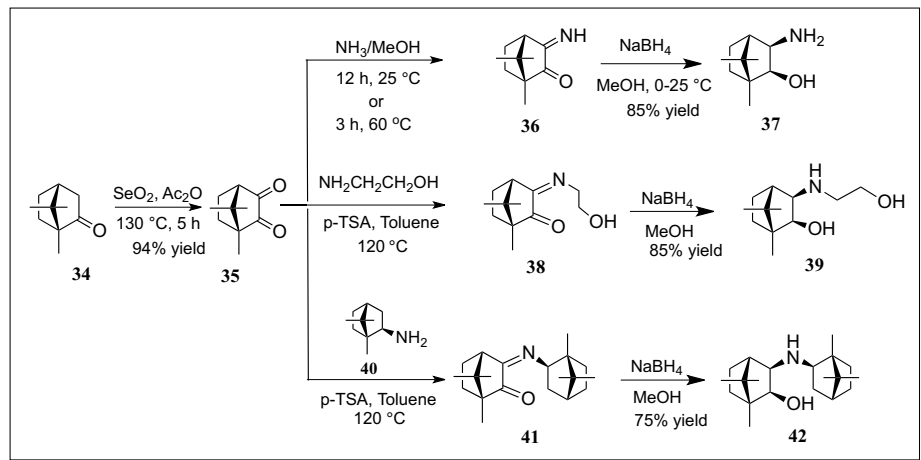

Scheme 5 .

\section{Synthesis of Chiral Amino Alcohol Derivatives via Opening of Cyclohexene Epoxide}

Amino alcohols can also be obtained by the stereo-, regio- and enantioselective ring opening of epoxides using nitrogen nucleophiles such as primary, secondary amines or azide in the presence of certain metal complexes. ${ }^{[12]}$ The racemic amino alcohols can be resolved by complexing with chiral Bronsted acid derivatives, enzymatic or kinetic resolution. ${ }^{[13]} \mathrm{We}$ have utilized the readily accessible chiral 1,1'-bi-2-naphthol (27) for the resolution of racemic amino alcohols. ${ }^{[14]}$ For example, the racemic trans- $( \pm)-2-($ pyrrolidinyl) cyclohexanol and its methyl ether 4 prepared using cyclohexene epoxide (32), were effectively resolved from chiral 1,1'-bi-2-naphthol (27) and boric acid in THF or $\mathrm{CH}_{3} \mathrm{CN}$ to obtain samples with up to $99 \%$ ee (Scheme 4). ${ }^{[15]}$

\section{Synthesis of Chiral Amino Alcohols through Resolution of Racemic Mixtures}

A method to access various racemic amino alcohol derivatives $\mathbf{3 0}$ has been developed in this laboratory by reduction of oxime esters using $\mathrm{NaBH}_{4} / \mathrm{I}_{2} \cdot{ }^{[10]}$ These aminoalcohols $\mathbf{3 0}$ are easily resolved using chiral dibenzoyl-L-tartaric acid to obtain partially resolved nonracemic samples. We have developed a conceptually new method for purification of the nonracemic amino alcohols to obtain samples of higher $e e$, through preparation of homochiral and heterochiral aggregates 31 using inexpensive achiral oxalic and fumaric acids (Scheme 3). ${ }^{11]}$

\section{Synthesis of Chiral Amino Alcohol Derivatives Starting from Camphor}

Chiral camphanyl derivatives are very useful in asymmetric transformations as chiral building blocks. ${ }^{[16]}$ Methods of synthesis of these derivatives involve multistep processes in most cases. ${ }^{[17]}$ Recently, we have developed efficient routes for preparing optically active amino alcohols via $\mathrm{NaBH}_{4}$ reduction of intermediates (-)-camphorquinone. ${ }^{[18]}$ For example, the prepared using the readily accessible $\mathrm{D}$ - 
reaction of $\mathrm{D}-(-)$-camphorquinone $(\mathbf{3 5})$ with methanolic ammonia followed by reduction with $\mathrm{NaBH}_{4}$ afforded the amino alcohol 37 as the only product in $85 \%$ yield. The D-(-)-camphorquinone imine derivatives 38 and 41 were also readily prepared using ethanol amine and isoboranyl amine (40) and converted to the amino alcohol derivatives 39 and $\mathbf{4 2}$ in 75-85\% yields by reduction with $\mathrm{NaBH}_{4}$ in methanol under ambient temperature (Scheme 5).

\section{Synthesis of Chiral Amino Naphthols}

The search for new chiral ligands with potential for use in asymmetric transformations is of great interest in modern organic chemistry research. ${ }^{[19]}$ In this context, chiral 1,2- and 1,3-amino phenols and naphthols were proved to be useful ligands in a variety of asymmetric transformations catalyzed by metal complexes. ${ }^{[20]}$ In 1900 , the preparation of amino naphthol (Betti base) 6 was reported by the condensation of 2-naphthol with ammonia and benzaldehyde. ${ }^{[21]}$ Since then numerous reports have been documented for accessing chiral Betti base derivatives and their applications in asymmetric transformations. ${ }^{[22]}$ In continuation of development of new methods of resolution to obtain important chiral reagents, ${ }^{[9,14]}$ we have developed a general method of synthesis of racemic amino naphthols 6 which are resolved using L-(+)-tartaric acid (Scheme 6). [23]

The chiral aminonaphthols 6 have been shown to be useful for the resolution of racemic bi-2-naphthol. ${ }^{[23]}$

\section{Synthesis of Chiral Pyrrolidine Derivatives Using (S)-Proline}

In 1969, (S)-2-(diphenylmethyl)pyrrolidine (43) was first reported as its hydrochloride salt in patent literature. It was prepared from $(S)$-proline. ${ }^{[24]}$ This amine 43 was used as a chiral solvating agent and in asymmetric organo catalysis. ${ }^{[25]}$ We have developed a convenient procedure involving borohydride reduction of the commercially available chiral $(S)$ $\alpha, \alpha$-diphenyl-2-pyrrolidinemethanol (Scheme 7). ${ }^{[26]}$

Chiral diamines like compound $\mathbf{4 6}$ are widely used in organocatalytic, enantioselective epoxide opening and other asymmetric transformations. ${ }^{[27]}$ We have developed a convenient method to access chiral $(S)$-1-(pyrrolidin-2-ylmethyl) piperidine (46) from $(S)$-proline (21). The corresponding $N$-phenyl derivative was accessed by $N$-phenylation using bromobenzene and sodium or lithium (Scheme 8). ${ }^{[28]}$

\section{Synthesis of Chiral Pyrrolidines Using $\alpha$-Methyl Benzylamine}

Meyers and Burgess reported the synthesis of enantiomerically pure 2-substituted pyrrolidines from $\gamma$-keto acid 49. ${ }^{[8]}$ Later, methods involving asymmetric deprotonation of $N$-boc-pyrrolidines and reductive cyclization of chiral $\gamma$-chloro $\mathrm{N}$-(tert-butanesulfinyl)ketimines were reported. ${ }^{[6,29]}$ We have performed the synthesis of chiral 2-substituted pyrrolidine skeletons $\mathbf{5 4}$ from $\beta$-benzoylpropanoic acid (49) by condensation with $(S)-\alpha$ - methylbenzylamine (51) and subsequent reduction using $\mathrm{NaBH}_{4} / \mathrm{I}_{2}$ (Scheme 9). [30]

\section{Synthesis of Chiral Pyrrolidine Systems through Asymmetric Borane Reductions}

The chiral (2S)-phenylpyrrolidine (7a) can be accessed through the CBS oxazaborolidine borane reduction in a crucial step. ${ }^{[31]}$ Thus, chiral (1R)-phenylbutan1,4-diol (56) obtained in $99 \%$ ee in CBS oxazaborolidine reduction of $\gamma$-keto ester 50, is readily converted to the chiral pyrrolidine $\mathbf{7 a}$ derivative through cyclization and $N$-deallylation using Wilkinson's catalyst in $82 \%$ yield with $96 \%$ ee (Scheme 10). ${ }^{[32]}$

Chiral $C_{2}$-symmetric molecules are widely used as auxiliaries and ligands in asymmetric tranformations. ${ }^{[33]}$ Chiral $C_{2}$ symmetric 2,5-disubstituted pyrrolidine derivatives are widely used in a variety of asymmetric transformations including alkylation, radical cyclizations, Michael addition, enantioselective deprotonation, Claisen rearrangements, Diels-Alder reactions, allylic substitutions, reduction of prochiral ketones and in other asymmetric hydrogenation reactions. ${ }^{[34]} \mathrm{We}$ have developed a synthetic method to access the chiral $C_{2}$-symmetric $(2 S, 5 S)-2,5$ diphenylpyrrolidine (7b) by utilizing the modified borohydride ${ }^{n} \mathrm{Bu}_{4} \mathrm{NBH}_{4}$ in combination with $\mathrm{I}_{2}$ or iodomethane for the reduction of 1,2 -dibenzoylethane $(\mathbf{5 9})$ in the presence of oxazaborolidine (60). ${ }^{[35]}$ Earlier, the amine $\mathbf{7 b}$ was accessed through $N$-deallylation using Wilkinson's

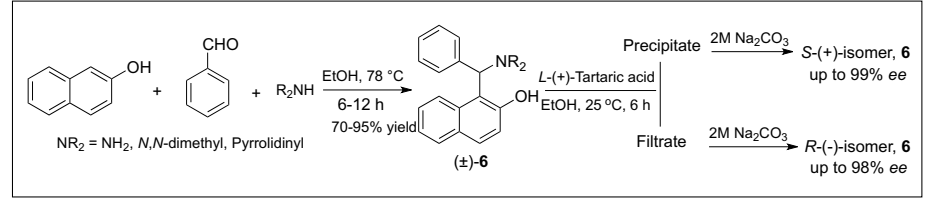

Scheme 6.

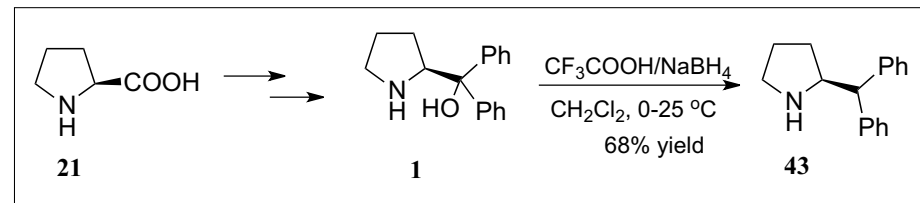

Scheme 7.

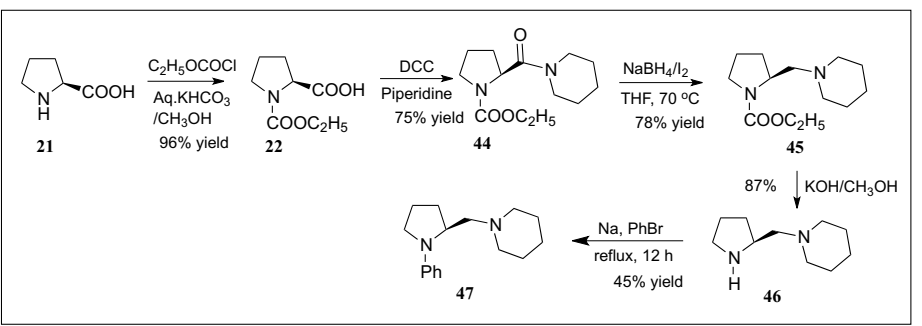

Scheme 8.

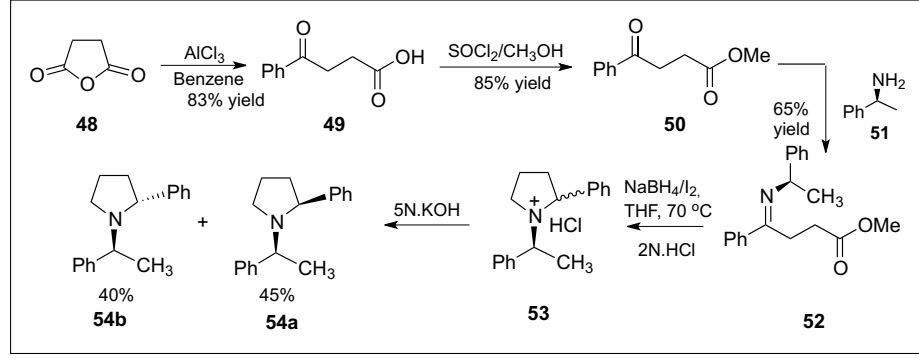

Scheme 9 .

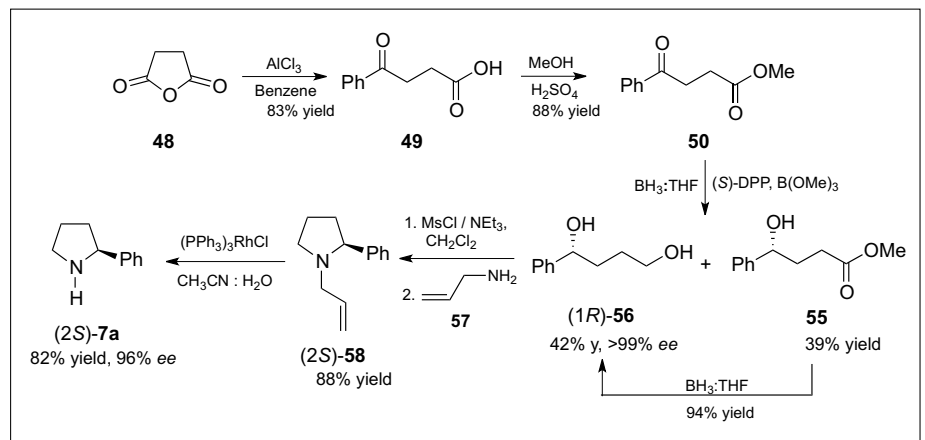

Scheme 10. 


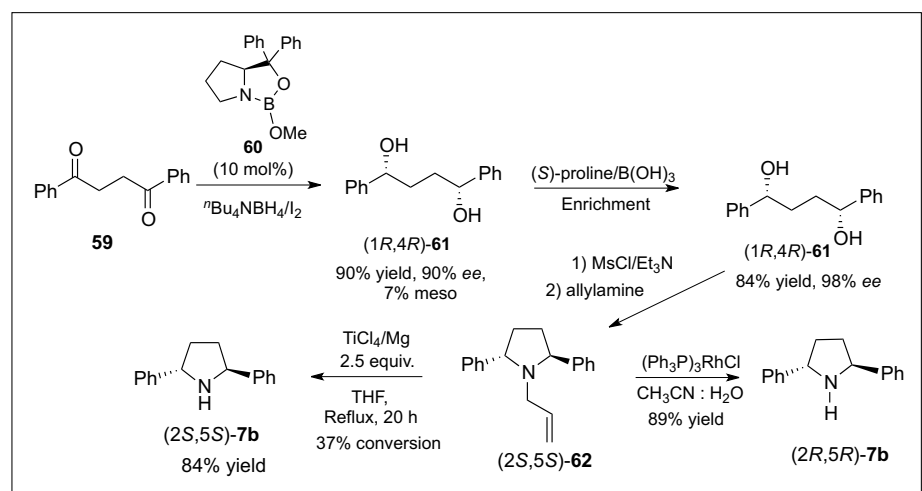

Scheme 11 .

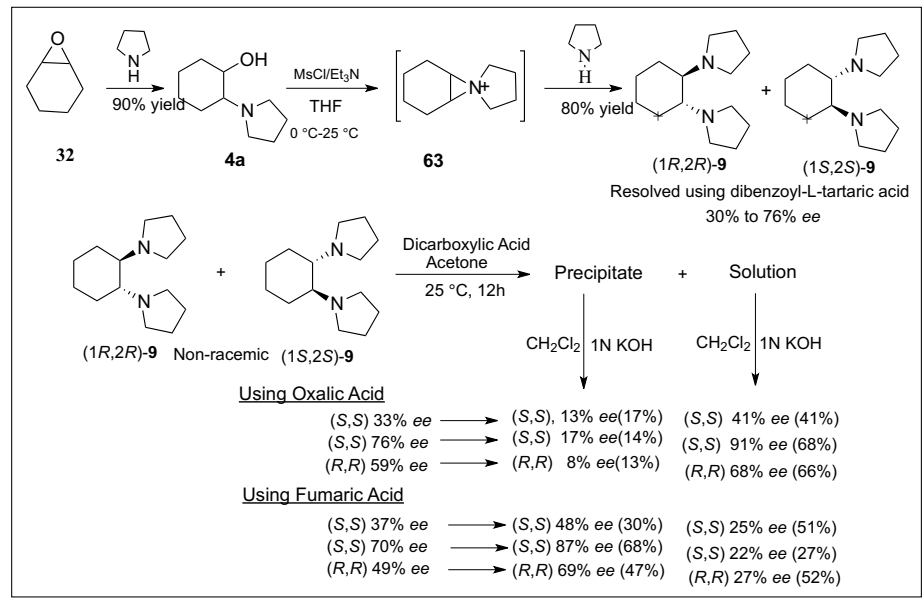

Scheme 12.

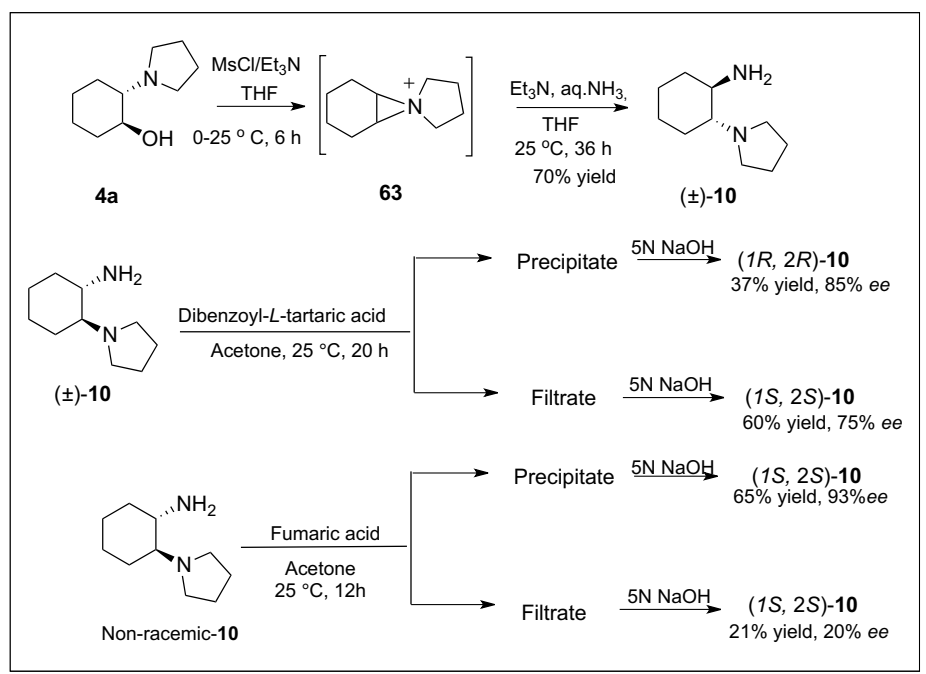

Scheme 13.

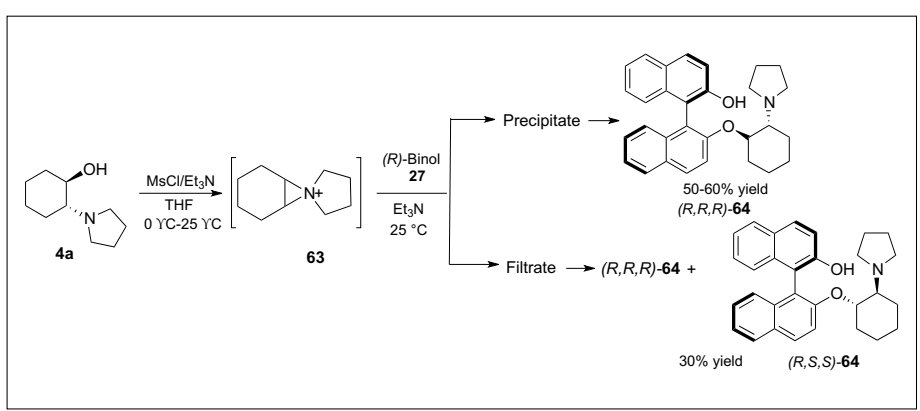

Scheme 14. catalyst.[31,36] We made an attempt to deallylate the chiral $(2 S, 5 S)-N$-allyl-2,5diphenylpyrrolidine (62) using inexpensive low valent titanium reagent system $\left(\mathrm{TiCl}_{4} / \mathrm{Mg}\right)$. However, the chiral pyrrolidine derivative $\mathbf{7 b}$ was obtained in $84 \%$ yield but the conversion was only up to $37 \%$ (Scheme 11). ${ }^{[37]}$

\section{Synthesis of Chiral Pyrrolidine Derivatives via Opening of Aziridinium Ions}

In recent years, several 1,2-diamine derivatives were found to be useful in medicinal chemistry and many natural products that have valuable biological properties contain a 1,2-diamino moiety. ${ }^{[38]}$ The chiral, enantiomerically pure 1,2-diamines and their derivatives are also used in stereoselective transformations as chiral auxiliaries, or as ligands in catalytic asymmetric synthesis.[33a] Methods have been reported for synthesis of vicinal diamines through opening of aziridinium ions. ${ }^{39]}$ In this laboratory, we have investigated the synthesis of various 1,2-diamine derivatives from aminoalcohols and their resolution using chiral acids. Thus, the racemic 1,2-di(pyrrolidin-1-yl)cyclohexane (9) was synthesized via sequential ring opening of cyclohexene oxide (32) and the meso aziridinium ion intermediate 63 prepared in situ using trans- $( \pm)-$ 2-(N,N-dialkyl-amino)cyclohexanol (4a) and pyrrolidine. The racemic diamine was resolved using chiral dibenzoyl-L-tartaric acid to obtain samples with up to $76 \%$ ee. The nonracemic mixture was enriched to obtain samples with up to $91 \%$ ee using achiral diacids through formation of novel diastereomeric aggregates (Scheme 12). ${ }^{[11]}$

In a similar way, the racemic trans- $( \pm)$ 1,2-diamine 10 was synthesized by opening the meso aziridinium intermediate $\mathbf{6 3}$ with ammonia. Racemic $\mathbf{1 0}$ was resolved using chiral dibenzoyl-L-tartaric acid with up to $82 \%$ ee and the non-racemic mixture was enriched using fumaric acid to obtain samples with up to $92 \% e e$ (Scheme 13). ${ }^{[40]}$

Following a similar protocol, the chiral 1,1'-bi-2-naphthol-derived amino ether 64 was synthesized through opening 63 (Scheme 14).[41]

\section{Synthesis of Camphanyl Diamines Using Methods Involving Reduction of Camphor Imines}

D-(+)-Camphor (34), D-(-)-camphorquinone (35) and their derivatives were widely used as chiral auxiliaries and ligands in various asymmetric transformations. ${ }^{[42]}$ We have developed a protocol for the synthesis of various chiral camphanyl amines. ${ }^{[18,43]}$ The bis-imine derivatives prepared using Lewis acid catalysts upon reduction using $\mathrm{NaBH}_{4}-\mathrm{NiCl}_{2} \cdot 6 \mathrm{H}_{2} \mathrm{O}$ (nickel boride prepared in situ), $\mathrm{NaBH}_{4} / \mathrm{MeOH}$ and ${ }^{\mathrm{n}} \mathrm{Bu}_{4} \mathrm{NBH}_{4} / \mathrm{I}_{2}$ gave the pure camphanyl diamines 12-14 in high diastereomeric excess (Scheme 15). ${ }^{[18]}$

\section{Synthesis Using Methods Involving Reduction of Camphanyl Diimines}

The camphanyl diamine (71) was previously prepared in low yields through a multistep synthetic protocol, which involves condensation of D-(-)-camphorquinone (35) with the expensive rac-1,2diphenyl-ethylenediamine, followed by reduction and deprotection. ${ }^{[44]}$ We have synthesized this auxiliary in two steps from $\mathrm{D}$-(-)-camphorquinone (35) via formation of the corresponding diimine using methanolic ammonia and $\mathrm{Ti}\left(\mathrm{OPr}^{i}\right)$, followed by reduction with $\mathrm{NaBH}_{4} / \mathrm{MeOH}$. The camphanyl diamines $\mathbf{1 5}$ and 16 were synthesized by similar protocols as outlined in Scheme 16. ${ }^{[18]}$ 


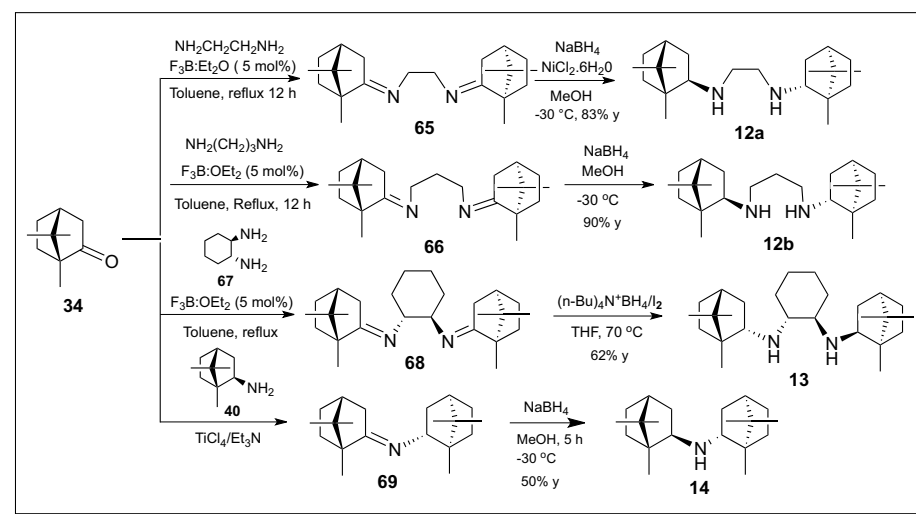

Scheme 15

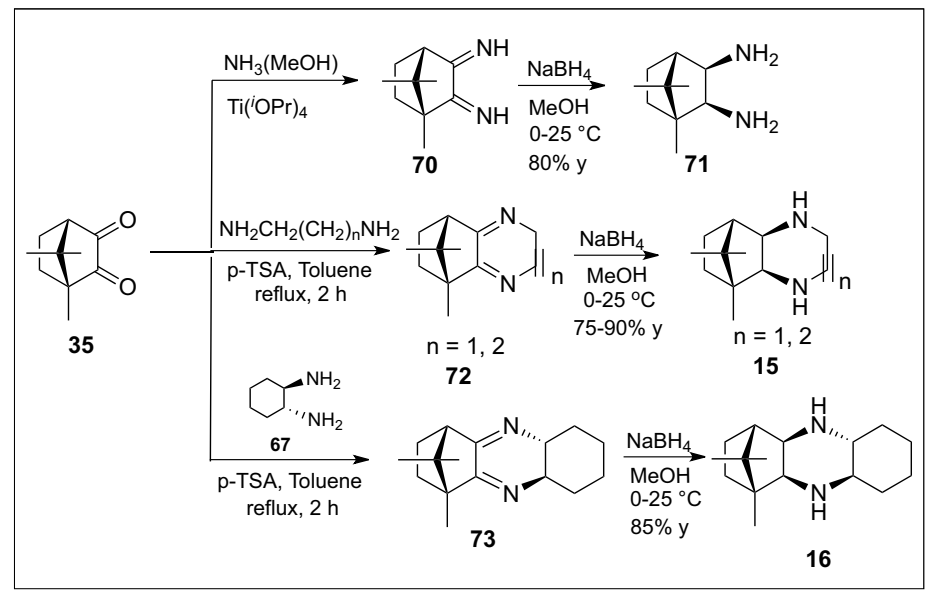

Scheme 16

\section{Synthesis of Chiral Amines Starting from 1,2-Diaminocyclohexane Derivatives}

The chiral macrocycles containing 1,2-diaminocyclohexane (67) moiety are useful as molecular receptors for peptides and in the enantiomeric recognition of amino acids. ${ }^{[45]}$ Also, the chiral 1,2-diaminocyclohexane derivatives were widely used as chiral ligands and catalysts in various asymmetric transformations. ${ }^{[46]} \mathrm{We}$ have developed methods for the synthesis of chiral macrocycles containing the chiral 1,2-diaminocyclohexanes 67 or its diisopropyl derivative $\mathbf{7 4}$, in some cases through formation of their amides, followed by reduction using $\mathrm{NaBH}_{4} / \mathrm{I}_{2}$ (Scheme 17 and 18). ${ }^{[47]}$

\section{Synthesis of Chiral Piperazines via Reductive Coupling Reactions}

Several methods have been reported from this laboratory for reductive coupling of imines using low valent titanium (LVT) reagents prepared using the $\mathrm{TiCl}_{4} / \mathrm{Mg}$ or $\mathrm{TiCl}_{4} / \mathrm{Et}_{3} \mathrm{~N}$ reagent systems. ${ }^{[48]}$ It was of interest to utilize the LVT reagents for intramolecular reductive coupling of chiral diimines. Accordingly, we have developed

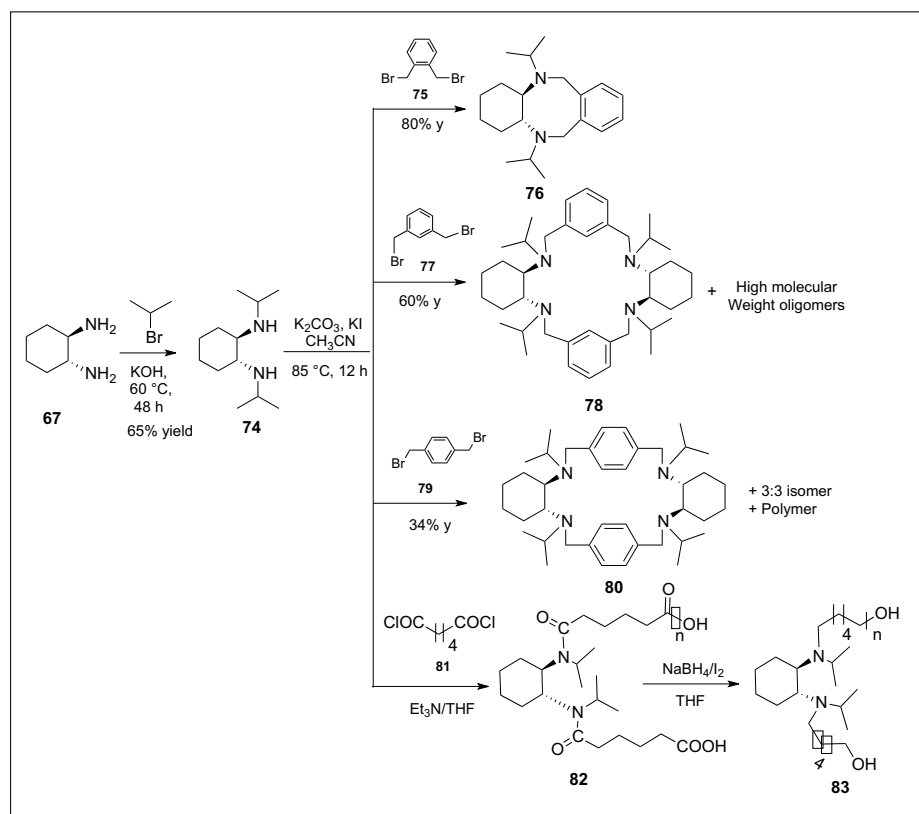

Scheme 17.

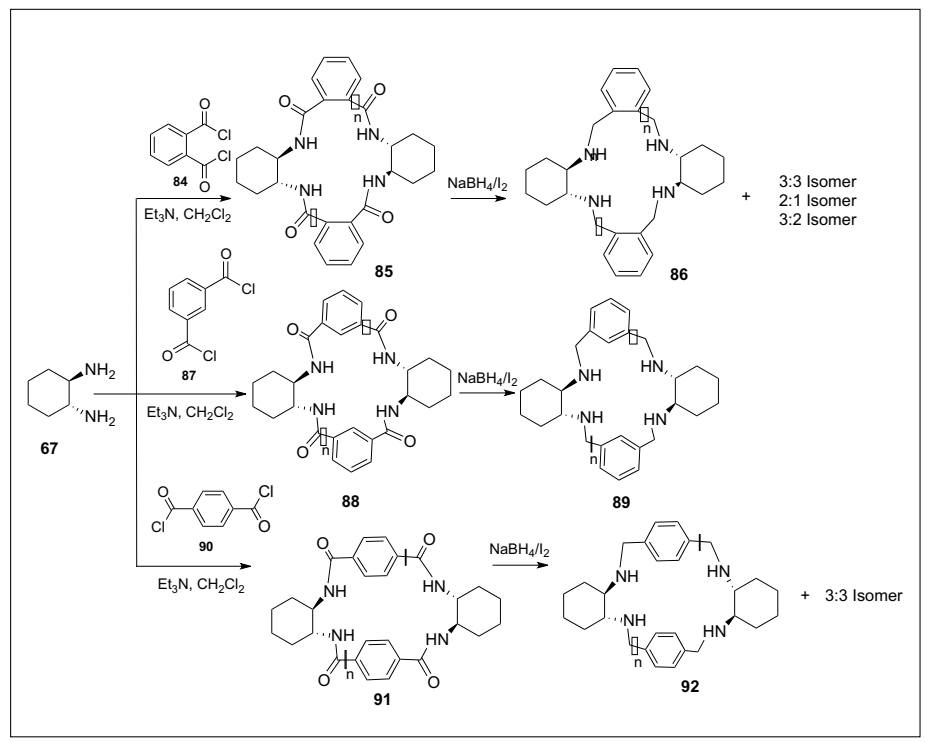

Scheme 18.

a method for diastereoselective reductive coupling of diimines 93 , prepared from 67 using $\mathrm{TiCl}_{4} / \mathrm{Zn}$. We have also reported a method for diastereoselective synthesis of trans-2,3-disubstituted piprazine $\mathbf{1 7}$ using $\mathrm{Ti}\left(\mathrm{OPr}^{i}\right)_{2} \mathrm{Cl}_{2} / \mathrm{Zn}$ reagent system and resolution of 2,3-disubstituted piperazine using L-(+)-tartaric acid as resolving agent. Furthermore, we have developed a method for enantioselective coupling of diimine 94 using chiral titanium complexes 95 to 2,3-disubstituted piperazines (Scheme 19). ${ }^{49]}$

\section{Synthesis of Chiral Bi-2- naphthyl Amine Derivatives}

Hogeveen et al. ${ }^{[50]}$ reported enantioselective reduction of prochiral ketones using a $C_{2}$-symmetrical amine- $\mathrm{BH}_{3}$ complex containing an $\alpha$-methylbenzyl moiety. We developed syntheses of such derivatives containing the chiral binaphthyl skeleton 8 (Scheme 20). ${ }^{[51]}$ We have observed that the amine 8 is useful in $\mathrm{BF}_{3}: \mathrm{Et}_{2} \mathrm{O}$-catalyzed asymmetric borane reduction of prochiral ketones to obtain the corresponding secondary alcohols with up to $57 \%$ ee..$^{[51]}$

\section{Synthesis of Chiral Tröger Base Derivatives}

The Tröger base $20(\mathrm{R}=\mathrm{Me})$, a molecule with two bridge head stereogenic nitrogen atoms exists in two enantiomeric forms. ${ }^{[52]}$ Due to its rigid and concave shape, it has attracted intense research in recent years. ${ }^{[53]}$ During our research efforts on development of new methods to access chiral amines, it has been discovered that reaction of para-substituted aniline de- 


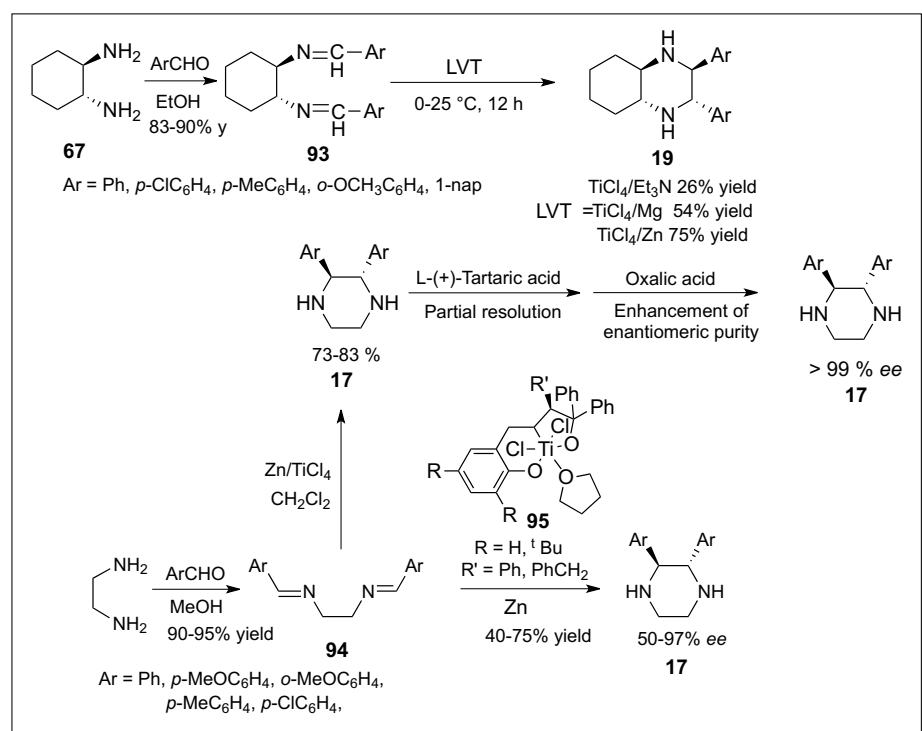

Scheme 19.

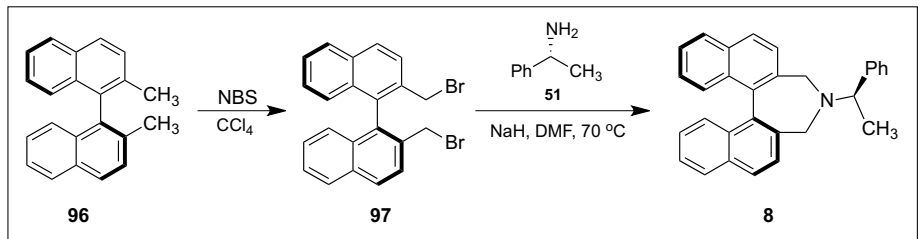

Scheme 20.

rivatives 98 with paraformaldehyde under Lewis acid catalysis gives the corresponding Tröger base derivatives $\mathbf{2 0}$. These racemic mixtures were readily resolved using dibenzoyl-L-tartaric acid as resolving agent (Scheme 21).[54]

A simple one-pot method has been developed for the preparation of new Tröger base derivatives 100 by an exchange reaction with the methano bridge of $\mathrm{rac}$ Tröger base derivatives 99 with carbonyl compounds in the presence of $\mathrm{TiCl}_{4}$ or $\mathrm{POCl}_{3}$. The use of chiral $(S, S)-N, N$-bis $(\alpha-$ methylbenzyl)formamide (101) as a carbonyl compound gave the corresponding methano Tröger base derivatives with the diastereomeric ratios of up to $77: 23$ (Scheme 22). ${ }^{[55]}$

\section{Conclusion and Outlook}

We have developed simple, convenient methods to access a variety of chiral amino alcohols and amines by means of the preparation of corresponding diastereomeric salts, borate complexes, diastereo- and enantioselective reduction and cyclization reactions. We anticipate that the methods described here would make these chiral derivatives readily accessible for further synthetic exploitation, especially for development of new enantioselective transformations. ${ }^{[32]}$

Received: October 27, 2012

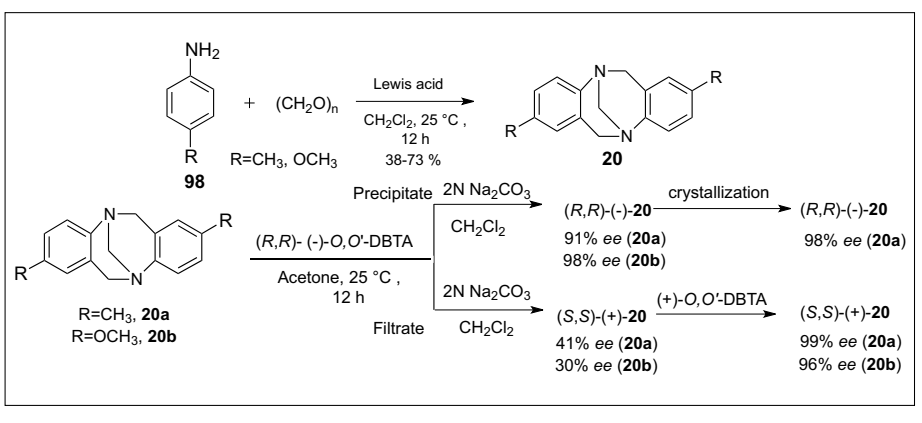

Scheme 21.

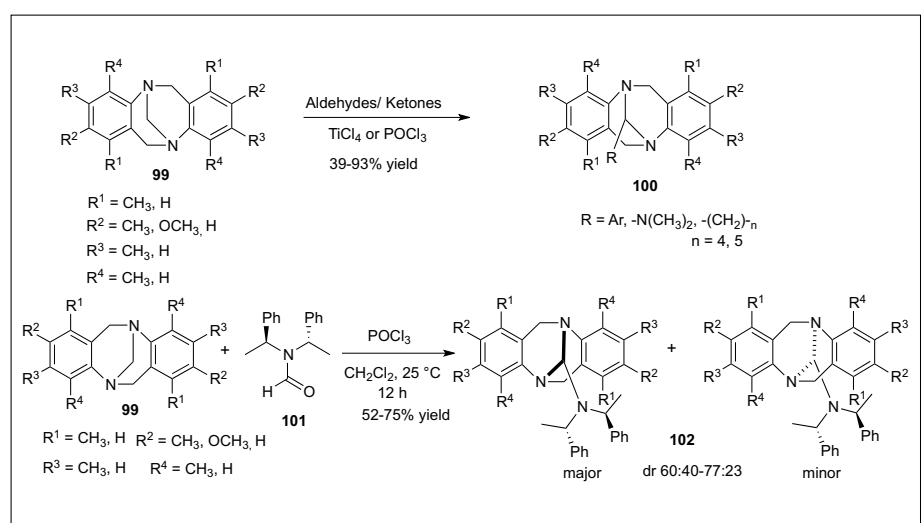

Scheme 22.
[1] a) R. Howe, R. G. Shanks, Nature, 1966, 210, 1336; b) A. Pohland, H. R. Sullivan, J. Am. Chem. Soc. 1953, 75, 4458; c) A. Pohland, L. R. Peters, H. R. Sullivan, J. Org. Chem. 1963, 28, 2483; d) E. J. Corey, J. O. Link, J. Org. Chem. 1991, 56, 442

[2] a) A. Abiko, S. Masamune, Tetrahedron Lett. 1992, 33, 5517; b) M. J. Mckennon, A. I. Meyers, J. Org. Chem. 1993, 58, 3568; c) H. Seki, K. Koga, H. Matsuo, S. Ohki, S. Yamada, Chem. Pharm. Bull. 1965, 13, 995.

[3] a) Y. Hayashi, H. Gotoh, T. Hayashi, M. Shoji, Angew. Chem., Int. Ed. 2005, 44, 4212; b) M. Marigo, T. C. Wabnitz, D. Fielenbach, K. A. Jørgensen, Angew. Chem., Int. Ed. 2005, 44, 794; c) S. Bertelsen, M. Marigo, S. Brandes, P. Diner, K. A. Jørgensen, J. Am. Chem. Soc. 2006, 128, 12973; d) P. Garcia-Garcia, A. Ladepeche, R. Halder, B. List, Angew. Chem., Int. Ed. 2008, 47, 4719. e) Y. Hayashi, T. Itoh, M. Ohkubo, H. Ishikawa, Angew. Chem., Int. Ed. 2008, 47, 4722.

[4] a) E. J. Corey, R. K. Bakshi, S. Shibata, J. Am. Chem. Soc. 1987, 109, 5551; b) E. J. Corey, R. K. Bakshi, S. Shibata, C.-P. Chen, V. K. Singh, J. Am. Chem. Soc. 1987, 109, 7925.

[5] E. J. Corey, S. Shibata, R. K. Bakshi, J. Org. Chem. 1988, 53, 2861

[6] P. Beak, S. T. Kerrick, S. Wu, J. Chu, J. Am. Chem. Soc. 1994, 116, 3231.

[7] J. V. B. Kanth, M. Periasamy, Tetrahedron 1993, 49, 5127.

[8] a) A. I. Meyers, L. E. Burgess, J. Org. Chem. 1991, 56, 2294; b) L. E. Burgess, A. I. Meyers, J. Org. Chem. 1992, 57, 1656.

[9] M Periasamy, N. S. Kumar, S. S. Kumar, V. D. Rao, C. R. Ramanathan, L. Venkatraman, $J$. Org. Chem. 2001, 66, 3828.

[10] M. Periasamy, S. Sivakumar, M. N. Reddy, Synthesis 2003, 1965.

[11] M. Periasamy, S. Sivakumar, M. N. Reddy, M. Padmaja, Org. Lett. 2004, 6, 265.

[12] a) L. E. Martinez, J. L. Leighton, D. H. Carsten, E. N. Jacobsen, J. Am. Chem. Soc. 1995, 117,
5897; b) W. A. Nugent, J. Am. Chem. Soc. 1992, 114, 2768; c) W. A. Nugent, J. Am. Chem. Soc. 1998, 120, 7139; d) H. Yamashita, Chem. Lett. 1987, 525; d) G. Sekar, V. K. Singh, J. Org. Chem. 1999, 64, 287.

[13] a) R. C. Kelly, I. Schletter, S. J. Stein, W. Wierenga, J. Am. Chem. Soc. 1979, 101, 1054; b) M. M. Gharpure, A. S. Rao, Synthesis 1988, 410 ; c) K. Faber, H. Honig, P. S. Wasserthal, Tetrahedron Lett. 1988, 29, 1903; d) S. Miyano, L. D. L. Lu, S. M. Viti, K. B. Sharpless, J. Org. Chem. 1983, 48, 3608.

[14] a) M. Periasamy, A. S. B. Prasad, J. V. B. Kanth, C. K. Reddy, Tetrahedron: Asymm. 1995, 6, 341; b) L. Venkatraman, M. Periasamy, Tetrahedron: Asymm. 1996, 7, 2471; c) M. Periasamy, C. R. Ramanathan, A. S. B. Prasad, J. V. B. Kanth, Enantiomer 1998, 3, 3; d) C. R. Ramanathan, M. Periasamy, Tetrahedron: Asymm. 1998, 9, 2651; e) M. Periasamy, L. Venkatraman, S. Sivakumar, N. S. Kumar, C. R. Ramanathan, J. Org. Chem. 1999, 64, 7643.

[15] M. Periasamy, C. R. Ramanathan, N. S. Kumar, Tetrahedron: Asymm. 1999, 10, 2307.

[16] a) L. Pu, H.-B. Yu, Chem. Rev. 2001, 101, 757; b) Y. Luo, H. Zhang, Y. Wang, P. Xu, Acc. Chem. Res. 2010, 43, 1317; c) G. Chelucci, Chem. Soc. Rev. 2006, 35, 1230.

[17] a) M. P. Bonner, E. R. Thornton, J. Am. Chem. Soc. 1991, 113, 1299; b) M. J. Bosiak, M. P. Krzeminski, P. Jaisankar, M. Zaidlewicz, Tetrahedron: Asymm. 2008, 19, 956.

[18] M. Periasamy, N. Sanjeevakumar, P. O. Reddy, Synthesis 2012, 3185.

[19] a) R. Noyori, 'Asymmetric Catalysis in Organic Synthesis', Wiley, New York, 1994; b) I. Ojima, 'Catalytic Asymmetric Synthesis', Ed. I. Ojima, VCH, New York, 1993; c) 'Comprehensive Asymmetric Catalysis', Eds. E. N. Jacobsen, A. Pfaltz, H. Yamamato, Springer, Berlin, 1999; d) G. Q. Lin, Y. M: Li, A. S. C. Chan, 'Principles and Applications of Asymmetric Synthesis', Wiley, New York, 2001.

[20] a) S. Vyskocil, S. Jaracz, M. Smrcina, M. 
Sticha, V. Hanus, M. Polasek, P. Kocovsky, J. Org. Chem. 1998, 63, 7727; b) C. Cimarelli, G Palmieri, E. Volpini, J. Org. Chem. 2003, 68, 1200; c) C. Cimarelli, G. Palmieri, E. Volpini, Tetrahedron: Asymm. 2002, 13, 2011.

[21] a) M. Betti, Gazz. Chim. Ital. 1900, 30 (II), 301; b) M. Betti, Gazz. Chim. Ital. 1900, 30 (II), 310; c) M. Betti, Organic Synthesis Collective 1941, 1,381 .

[22] a) C. Cardellicchio, G. Ciccarella, F. Naso, F. Perna, P. Tortorella, Tetrahedron 1999, 55, 14685; b) C. Cimarelli, A. Mazzanti, G. Palmieri, E. Volpini, J. Org. Chem. 2001, 66, 4759; c) J.-X. Ji, L.-Q. Qui, C. W. Yip, A. C. S. Chan, J. Org. Chem. 2003, 68, 1589.

[23] M. Periasamy, M. N. Reddy, S. Anwar, Tetrahedron: Asymm. 2004, 15, 1809.

[24] a) Roussel-UCLAF, Patent [Fr. M. 3,638], 1964 [Chem. Abs., 1969, 70, 106375m]; b) D. Enders, H. Kipphardt, P. Gerdes, L. J. Brena-Valle, V. Bhushan, Bull. Soc. Chim. Belg. 1988, 97 691 ; c) D. J. Bailey, D. O’Hagan, M. Tavasli, Tetrahedron: Asymm. 1997, 8, 149.

[25] a) K. Juhl, K. A. Jørgensen, Angew. Chem., Int. Ed. 2003, 42, 1498; b) P. Melchiorre, K. A. Jørgensen, J. Org. Chem. 2003, 68, 4151 .

[26] S. Anwar, Ph.D. Thesis, 2008, University of Hyderabad.

[27] a) M. Asami, Bull. Chem. Soc. Jpn. 1990, 63, 721; b) M. Nakajima, I. Miyoshi, K. Kanayama, S-I. Hashimoto, M. Noji, K. Koga, J. Org. Chem. 1999, 64, 2264.

[28] J. V. B. Kanth, M. Periasamy, J. Org. Chem. 1993, 58, 3156.

[29] a) S. Wu, S. Lee, P. Beak, J. Am. Chem. Soc. 1996, 118, 715; b) E. Leemans, S. Mangelinckxz, N. D. Kimpe, Chem. Commn. 2010, 46, 3122 .

[30] C. K. Reddy, M. Periasamy, Synth. Commn. 1995, 25, 995 .

[31] D. J. Aldous, W. M. Dutton, P. G. Steel, Tetrahedron: Asymm. 2000, 11, 2455.

[32] M. Periasamy, N. Sanjeevakumar, M. Dalai, R. Gurubrahamam, P. O. Reddy, Org. Lett. 2012, 14, 2932.

[33] a) J. K. Whitesell, Chem. Rev. 1989, 89, 1581; b) I. Hargittai, M. Hargittai, 'Symmetry through the eyes of a chemist', VCH publishers, New York, 1987.

[34] a) N. Halland, A. Braunton, S. Bachmann, M. Marigo, K. A. Jorgensen, J. Am. Chem. Soc 2004, 126, 4790; b) S. Bertelsen, N. Halland, S. Bachmann, M. Marigo, A. Braunton, K A. Jorgensen, Chem. Commun. 2005, 4821; c) S. A. Kozmin, V. H. Rawal, J. Am. Chem. Soc. 1997, 119, 7165; d) S. A. Kozmin, V. H. Rawal, J. Am. Chem. Soc. 1999, 121, 9562; e) S. He, S. A. Kozmin, V. H. Rawal, J. Am. Chem. Soc. 2000, 122, 190; f) A. Duursma, R. Hoen, J. Schuppan, R. Hulst, A. J. Minnaard, B. L. Feringa, Org. Lett. 2003, 5, 3111; g) R. Hoen, M. V. D. Berg, H. Bernsmann, A. J. Minnaard, J. G. De Vries, B. L. Feringa, Org. Lett. 2004, 6, 1433.

[35] a) M. Periasamy, R. Gurubrahamam, G. P. Muthukumaragopal, Synthesis 2009, 1739; b) S. Anwar, M. Periasamy, Tetrahedron: Asymm. 2006, 17, 3244; c) M. Periasamy, G. P. Muthukumaragopal, N. Sanjeevakumar, Tetrahedron Lett. 2007, 48, 6966; d) M. Periasamy, M. Seenivasaperumal, V. D. Rao, Synthesis 2003, 2507.

[36] J. M. Chong, I. S. Clarke, I. Koch, P. C. Olbach, N. J. Taylor, Tetrahedron: Asymm. 1995, 6, 409; b) X. Li, G. Zhao, W.-G. Cao, Chin. J. Chem. 2006, 24, 1402.

[37] R. Gurubrahamam, Ph.D. Thesis 2012, University of Hyderabad.

[38] A. Marquet, Pure Appl. Chem. 1993, 65, 1249; b) B. Rosenberg, L. VanCamp, J. E. Trosko, V. H. Mansour, Nature 1969, 222, 385; c) A Pasini, F. Zunino, Angew. Chem., Int. Ed. Engl. 1987, 26, 615; d) H. Brunner, P. Hankofer, U. Holzinger, B. Treittinger, H. Schönenberger, Eur. J. Med. Chem. 1990, 25, 35.

[39] a) R. K. Dieter, N. Deo, B. Lagu, J. W. Dieter, J. Org. Chem. 1992, 57, 1663; b) G. Miao, B. E. Rossiter, J. Org. Chem. 1995, 60, 8424; c) P. O'Brien, P. Poumellec, Tetrahedron Lett. 1996, 37, 5619; d) S. E. de Sousa, P. O'Brien, Tetrahedron Lett. 1997, 38, 4885; e) S. E. de Sousa, P. O'Brien P. Poumellec, Tetrahedron: Asymm. 1997, 8, 2613; f) S. E. de Sousa, P. O'Brien, P. Poumellec, J. Chem. Soc., Perkin Trans. 1 1998, 1483; g) B. Colman, S. E. De sousa, P. O'Brien, T. D. Towers, W. Watson, Tetrahedron: Asymm. 1999, 10, 4175; h) P. Saravanan, V. K. Singh, Tetrahedron Lett. 1998, 39, 167.

[40] M. Periasamy, M. Seenivasaperumal, M. Padmaja, V. D. Rao, ARKIVOC 2004, 8, 4.

[41] M. Periasamy, M. S. Perumal, V. D. Rao, Tetrahedron: Asymm. 2004, 15, 3847.

[42] C. L. K. Lee, C. H. A. Lee, K. T. Tan, T. P. Loh, H. S. Cheng, Org. Lett. 2004, 6, 1281; b) M. Sugiura, C. Mori, S. Kobayashi, J. Am. Chem. Soc. 2006, 128, 11038; c) H. Lachance, X. Lu, M. Gravel, D. G. Hall, J. Am. Chem. Soc. 2003,
125, 10160; d) M. P. Bonner, E. R. Thornton, J. Am. Chem. Soc. 1991, 113, 1299; e) A. E. Lurain, A. Maestri, A. R. Kelly, P. J. Carroll, P. J. Walsh, J. Am. Chem. Soc. 2004, 126, 13608 ; f) A. E. Lurain, P. J. Walsh, J. Am. Chem. Soc. 2003, 125, 10677; g) Y. Li, Z. Feng, S.-L. You, Chem. Commun. 2008, 2263; h) Y. Li, X.-Q Wang, C. Zheng, S.-L. You, Chem. Commun. 2009, 5823; i) P. V. G. Reddy, S. Tabassum, A. Blanrue, R. Wilhelm, Chem. Commun. 2009, 5910.

[43] M. Periasamy, A. Devasagayaraj, N. Satyanarayana, C. Narayana, Synth. Commun. 1989, 19, 565.

[44] C. A. Busacca, S. Campbell, Y. Dong, D Grossbach, M. Ridges, L. Smith, E. Spinelli, J Org. Chem. 2000, 65, 4753.

[45] a) Z. Pan, W. C. Still, Tetrahedron Lett. 1996 37, 8699; b) W. C. Still, Acc. Chem. Res. 1996, 29, 155; c) K. H. Lee, D. H. Lee, S. Hwang, O. S. Lee, D. S. Chung, J.-I. Hong, Org. Lett. 2003 5, 1431.

[46] Y. L. Bennani, S. Hanessian, Chem. Rev. 1997, 97, 3161.

[47] a) M. Padmaja, M. Periasamy, Tetrahedron: Asymm. 2004, 15, 2437; b) M. Periasamy, M. Dalai, M. Padmaja, J. Chem. Sci. 2010 , 122, 561; c) M. Padmaja, Ph.D. Thesis 2005 University of Hyderabad.

[48] a) M. Periasamy, M. R. Reddy, J. V. B. Kanth, Tetrahedron Lett. 1996, 37, 4767; b) M. Periasamy, G. Srinivas, G. V. Karunakar, P. Bharathi, Tetrahedron Lett. 1999, 40, 7577.

[49] a) M. Periasamy, G. Srinivas, S. Suresh, Tetraheron Lett. 2001, 42, 7123; b) P. Vairaprakash, M. Periasamy, J. Org. Chem. 2006, 71, 3636; c) P. Vairaprakash, M. Periasamy, Tetrahedron Lett. 2008, 49, 1233.

[50] M. B. Eleveld, H. Hogeveen, Tetrahedron Lett. 1986, 27, 635 .

[51] J. V. B. Kanth, M. Periasamy, J. Chem. Soc. Chem. Commun. 1990, 1145.

[52] J. Tröger, J. Perkt. Chem. 1887, 36, 225.

[53] a) B. Dolensky, J. Elguero, V. Kral, C. Pardo, M. Valik, Adv. Heterocycl. Chem. 2007, 93, 1; b) S. Sergeyev, Helv. Chim. Acta. 2009, 92, 415

[54] a) S. Satishkumar, M. Periasamy, Tetrahedron: Asymm. 2006, 17, 1116; b) S. Satishkumar, M. Periasamy, Tetrahedron: Asymm. 2009, 20, 2257.

[55] M. Periasamy, S. Suresh, S. Satishkumar, Tetrahedron: Asymm. 2012, 23, 108. 